Article

\title{
Spatial and Temporal Variations of Potential Evapotranspiration in the Loess Plateau of China During 1960-2017
}

\author{
Congjian Sun ${ }^{1, *(1)}$, Zhenjing Zheng ${ }^{1, *}$, Wei Chen ${ }^{1}$ and Yuyang Wang ${ }^{2}$ \\ 1 School of Geographical Science, Shanxi Normal University, Linfen 041000, China; wan_xin_chen@126.com \\ 2 Institute of Tibetan Plateau Research, University of Chinese Academy of Sciences, Beijing 100049, China; \\ wangyuyang@itpcas.ac.cn \\ * Correspondence: suncongjian@sina.com (C.S.); zhengzjsxnu@sina.com (Z.Z.); \\ Tel.: +86-1863-479-4965 (C.S.); +86-188-3573-8081 (Z.Z.)
}

Received: 11 December 2019; Accepted: 31 December 2019; Published: 2 January 2020

\begin{abstract}
Potential evapotranspiration $\left(\mathrm{ET}_{0}\right)$ is an integral component of the hydrological cycle and the global energy balance, and its long-term variation is of much concern in climate change studies. The Loess Plateau is an important area of agricultural civilization and water resources research. This study analyzed the spatial and temporal evolution processes and influential parameters of $\mathrm{ET}_{0}$ at 70 stations in different topographical areas of the Chinese Loess Plateau (CLP). Using the Mann-Kendall trend, Cross wavelet transform, and the ArcGIS platform, the $\mathrm{ET}_{0}$ of each station was quantified using the Penman-Monteith equation, and the effects of climatic factors on $\mathrm{ET}_{0}$ were assessed by analyzing the correlation coefficients and contribution rates of the climatic factors. The results showed that: (1) the overall trend of the $\mathrm{ET}_{0}$ in different terrains of the Loess Plateau is consistent, however, the $\mathrm{ET}_{0}$ values differ; the hill region (HR) has the highest $\mathrm{ET}_{0}$, followed by the valley region (VR), and the mountain region (MR) has the lowest, and $\mathrm{ET}_{0}$ changes differ between seasons. (2) Spatial distribution characteristics of multiyear mean $\mathrm{ET}_{0}$ in the study are as follows: the $\mathrm{ET}_{0}$ values in mountain and hilly areas are decreasing from west to east, and the higher mean annual $\mathrm{ET}_{0}$ value in the VR is mainly concentrated in the eastern CLP. (3) In the past 58 years, the annual mean and the seasonal $\mathrm{ET}_{0}$ of the region showed increasing trends, however, differences in different terrains were obvious. (4) $\mathrm{ET}_{0}$ has significant correlations with El Niño-Southern Oscillation (ENSO), Pacific-North American teleconnection (PNA), and Atlantic Multidecadal Oscillation (AMO). The resonance period of $\mathrm{ET}_{0}$ and ENSO was 3-6 a, mainly in 1976-1985. The mean coherence phase angle was close to $360^{\circ}$, indicating that $\mathrm{ET}_{0}$ lags behind PNA by approximately 2-6 a; $\mathrm{ET}_{0}$ has a very strong positive correlation with AMO. (5) Relative humidity (RH) is the main influencing factor of $\mathrm{ET}_{0}$ change in the Loess Plateau. Temperature $(\mathrm{T})$ variation has the highest contribution rate $(42 \%)$ to the regional $\mathrm{ET}_{0}$ variation in the entire CLP. We should pay more attention to the variation of evaporation under future climate change, especially temperature change.
\end{abstract}

Keywords: potential evapotranspiration; Penman-Monteith model; temporal-spatial distribution; controlling parameters; Loess Plateau

\section{Introduction}

Potential evapotranspiration $\left(\mathrm{ET}_{0}\right)$ is an important parameter of hydrological processes and is closely related to regional precipitation and energy spatial distribution [1,2]. With the changing global climate, rising temperatures will further result in increasing rates of water circulation which further change regional climate patterns [3-5]. The global temperature has a significant increasing 
trend over the past decade. Rising temperature has proven to have a remarkable influence on the regional $\mathrm{ET}_{0}$ variation, which caused the frequency of global heat waves and agricultural drought to increase, and the chance of a damaging hot spell for food production also increased significantly $[6,7]$. Besides, disordered human activities had a serious impact on regional evapotranspiration variation and further reduced plant cover and agricultural production $[8,9]$. Assessment of regional $\mathrm{ET}_{0}$ is not only essential for understanding the energy balance in the earth-atmospheric system but also has a key role in understanding hydrological processes and climate change. Previous research has provided numerous useful methods to evaluate the variation of the regional $\mathrm{ET}_{0}$, including the Penman-Monteith (PM) method [10], the Hargreaves method [11], the Priestley-Taylor method [12], and other empirical methods [13]. Due to the accessibility of input data and wide applicability, the PM method is recommended by the Food and Agriculture Organization (FAO) and is widely used for assessing spatial-temporal $\mathrm{ET}_{0}$ variations during various climate scenarios and the response to variations in environmental factors [14,15].

Several researchers [16-18] have reported on case studies of regional $\mathrm{ET}_{0}$ variations throughout the world. For example, the regional $\mathrm{ET}_{0}$ of eastern Europe has been proven to have had a significant increasing trend during 1961-2012 [19]. In Australia, obvious variability can be observed in the regional $\mathrm{ET}_{0}$ during 1995-2004, during which time the regional $\mathrm{ET}_{0}$ ranged from $699 \mathrm{~mm}$ to $2634 \mathrm{~mm}$ [20]. Similar research has been carried out in various regions [21,22]. These studies indicated that the regional $\mathrm{ET}_{0}$ has had significant changes over recent decades. Besides, an increasing number of studies have indicated close relationships between the variations of regional $\mathrm{ET}_{0}$ and environmental factors (e.g., meteorological parameters, circulation parameters, and terrain parameters) [23-25]. According to previous reports, meteorological parameters have been considered as important controlling factors. Based on an investigation of 500 Chinese meteorological stations between 1956 and 2000, Gao et al. [26] highlighted the importance of temperature, sunshine duration, wind speed, and relative humidity on the evapotranspiration. Liu et al. [23] indicated that wind speed variation is the main controlling factor for $\mathrm{ET}_{0}$ variations in Gansu. In the Hengduan Mountains, research has found that the $\mathrm{ET}_{0}$ variation was related to variations in regional temperature, wind speed, and sunshine duration [24].

Nowadays, an increasing amount of research has indicated that circulation parameters are related to variations in regional climate patterns $[25,27,28]$. Gong et al. [29] found that regional temperature fluctuation is significantly associated with variation of the North Atlantic Oscillation (NAO), the North Pacific Oscillation (NPO), and the Southern Oscillation (SO). Li et al. [30] reported that the Arctic Oscillation $(\mathrm{AO})$ has a remarkable influence on the precipitation structure in some typical catchments, and results in regional $\mathrm{ET}_{0}$ variations. Besides, some studies pointed out that the regional $\mathrm{ET}_{0}$ of China, with different topographic conditions, usually appeared with obvious spatial variability. For example, Yao et al. [31] found that the $\mathrm{ET}_{0}$ in the arid and subtropical regions of northwest China is higher, while the values of the $\mathrm{ET}_{0}$ in the northeast and the Qinghai-Tibet Plateau are relatively low. Li et al. [30] concluded that the areas with higher $\mathrm{ET}_{0}$ values are mainly in the Tibetan Plateau, Hengduan Mountains, and Yunnan Plateau, whereas the $\mathrm{ET}_{0}$ values in the Guizhou Plateau and Sichuan Basin are lower (a siginificant evaporation paradox [28] can be observed).

In China, temporal and spatial variations of regional $\mathrm{ET}_{0}$ of some typical regions were also systematically evaluated. For example, Wang et al. [32] calculated $\mathrm{ET}_{0}$ values and estimated the temporal and spatial variation of the Hexi region in northwestern China. Zhou et al. [33] analyzed the variation of $\mathrm{ET}_{0}$ in southwestern China and found that the $\mathrm{ET}_{0}$ values during recent decades showed a significant increasing trend. These studies provide important information for assessing the influence of regional climate change and understanding regional hydrological processes. However, few studies have focused on evaluating $\mathrm{ET}_{0}$ variations in the Chinese Loess Plateau (CLP). Some studies focus on the $\mathrm{ET}_{0}$ variations in individual regions of the CLP $[34,35]$. Temporal and spatial variations of regional $\mathrm{ET}_{0}$ under different geomorphic types and the relationships with the main controlling factors remain unclear. The CLP is an important geomorphic region in Asia, and the thick, sedimentary loess is a useful material for reconstruction of paleoclimate and studying climate change. As an important 
place of origin of world agricultural civilization, the fragile ecological environment in the CLP is very sensitive to climate change. Therefore, it is necessary to improve our understanding of the temporal and spatial characteristics of regional $\mathrm{ET}_{0}$ in the CLP. In this study, data from 70 weather stations with three topography types in the CLP during 1960-2017 were used to analyze spatial and temporal $\mathrm{ET}_{0}$ variations. The main objectives of this study were to: (1) analyze the temporal and spatial variation characteristics of the $\mathrm{ET}_{0}$ with different topographies in the CLP; (2) determine the main controlling factors of the variations of regional $\mathrm{ET}_{0}$ with different topographies in the CLP; and (3) determine the relationship between regional $\mathrm{ET}_{0}$ of the CLP and larger-scale circulation parameters. The results of this study will be of great significance to improve our understanding of regional hydrological processes and regional water resource management.

\section{Methods}

\subsection{Study Area}

In the current study, the CLP was defined as the area between $33^{\circ} 43^{\prime}-41^{\circ} 16^{\prime} \mathrm{N}$ and $100^{\circ} 54^{\prime}-114^{\circ} 33^{\prime}$ $\mathrm{E}$ [36] and has three geomorphic units: the mountain region (MR, including Qin Ling Mountains in the southern CLP, Wu Shao Ling Mountains in the western CLP, and Taihang Mountains and Luliang Mountains in the eastern CLP), the valley region (VR, including Hetao Basin in the northern CLP, Weihe Basin in the southern CLP, Yinchuan Basin in the western CLP, and Fenhe Basin in the eastern CLP), and the hill region (HR, mainly concentrated in the inner part of the CLP) (Figure 1). The area is approximately $64 \times 10^{4} \mathrm{~km}^{2}$, which is approximately $6.67 \%$ of the total area of China. The terrain of the CLP is high in the southwest region and low in the southeast. Based on long-term observation data from 70 national meteorological observatory stations in and around the CLP, we found the mean annual temperatures ranging from 3.6 to $14.3^{\circ} \mathrm{C}$ and annual precipitation ranging from 150 to $750 \mathrm{~mm}$. The soil type is mainly brown soil and cinnamon soil. Vegetation types are diverse and are mainly grassland, woodland (the categories of trees in the CLP mainly include Chinese catalpa, cypress, and Chinese prickly ash), and arable land [37]. The CLP has a long history of agricultural cultivation and its main types of crop producation are wheat and millet [38].
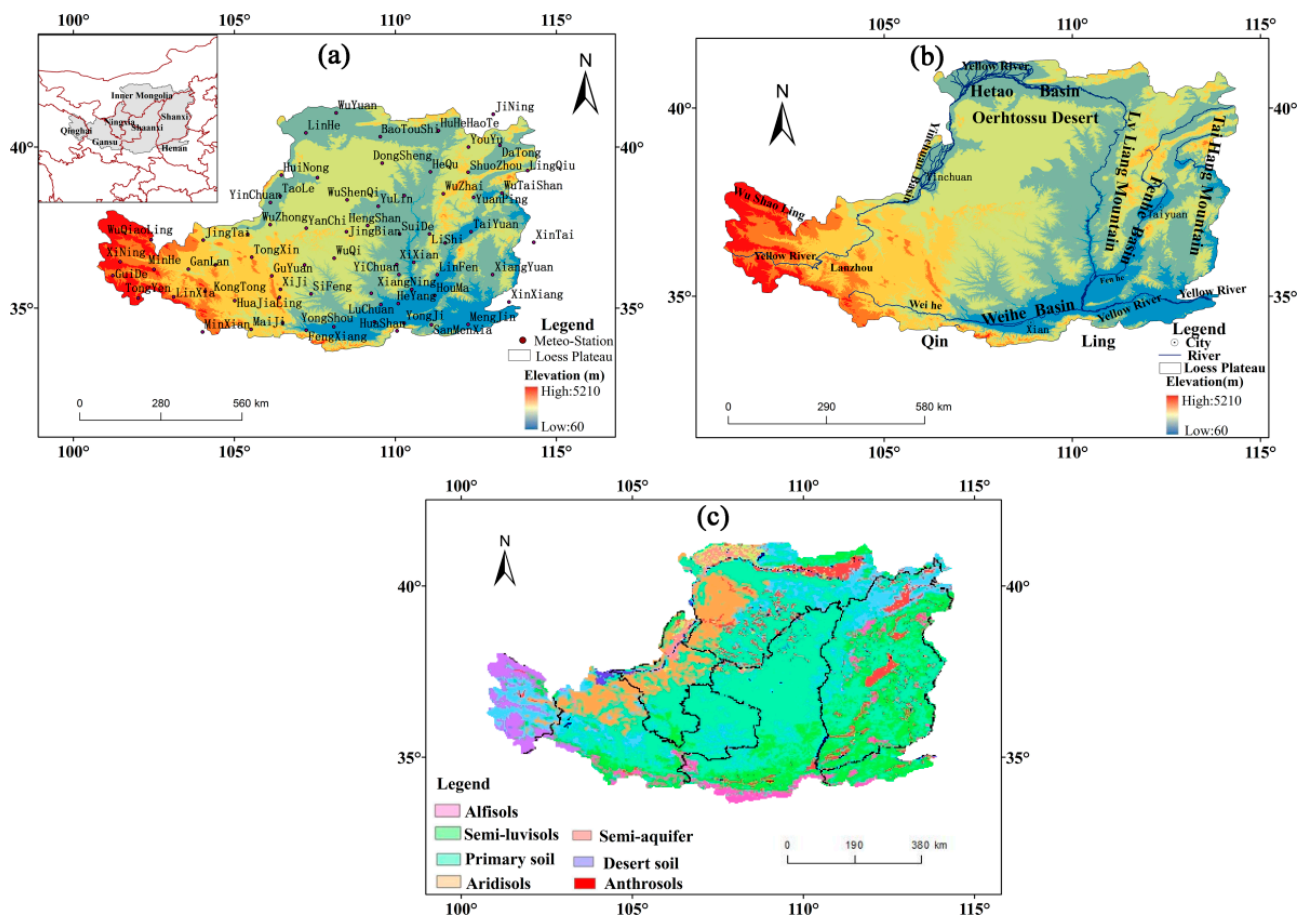

Figure 1. Topography and meteorological stations distribution map of the Loess Plateau; (a) meteorogical stations location information, (b) topography information, (c) soil map. 


\subsection{Data}

This study used continuous daily series data from 1960 to 2017 at 70 national meteorological observatory stations in and around the CLP (Table 1). Data included wind speed (WS) (m/s), sunshine duration $(\mathrm{SD})(\mathrm{h})$, daily mean temperature $(\mathrm{T})\left({ }^{\circ} \mathrm{C}\right)$, daily maximum temperature (Tmax) $\left({ }^{\circ} \mathrm{C}\right)$, daily minimum temperature $(\operatorname{Tmin})\left({ }^{\circ} \mathrm{C}\right)$, and relative humidity $(\mathrm{RH})(\%)$. Data were provided by the China Meteorological Administration (http://data.cma.cn/site/index.html). Large-scale circulation parameters data were downloaded from the National Oceanic and Atmospheric Administration (http://www.esrl.noaa.gov/psd/data/climateindices). Four seasons were divided in this study as: spring (March to May), summer (June to August), autumn (September to November), and winter (December to February).

Table 1. Basic information of meteorological stations used in this study.

\begin{tabular}{ccccccc}
\hline Study Areas & Altitude $(\mathbf{m})$ & $\mathbf{T}\left({ }^{\circ} \mathbf{C}\right)$ & $\mathbf{R H}(\mathbf{\%})$ & SD & WS (m/s) & ET $_{\mathbf{0}}(\mathbf{m m})$ \\
\hline CLP & 1224 & 8.76 & 58 & 7.12 & 2.99 & 1074.06 \\
MR region & 1970 & 5.88 & 61 & 6.98 & 2.67 & 936.86 \\
VR region & 891 & 9.99 & 58 & 7.04 & 2.16 & 1085.92 \\
HR region & 1098 & 9.33 & 56 & 7.32 & 2.46 & 1069.19 \\
\hline
\end{tabular}

\subsection{Methods}

\subsection{1. $\mathrm{ET}_{0}$ Calculation Method}

In this study, the FAO Penman-Monteith method [13] was used to estimate $\mathrm{ET}_{0}$ variations. The FAO-PM equation to calculate $\mathrm{ET}_{0}\left(\mathrm{~mm}^{- \text {day }^{-1}}\right)$ is given as:

$$
\mathrm{ET}_{0}=\frac{0.408 \Delta\left(R_{n}-G\right)+\gamma \frac{900}{T+273} u_{2}\left(e_{s}-e_{a}\right)}{\Delta+\gamma\left(1+0.34 u_{2}\right)}
$$

where $\mathrm{ET}_{0}$ is the daily potential evapotranspiration rate, $\mathrm{mm} \cdot \mathrm{d}^{-1} ; \Delta$ is the slope of the saturation vapor pressure curve, $\mathrm{K} P_{a} \cdot{ }^{\circ} \mathrm{C}^{-1} ; \mathrm{Rn}$ is the net radiation, $\mathrm{MJ} \cdot \mathrm{m}^{-2} \cdot \mathrm{d}^{-1} ; G$ is the soil heat flux density, $\mathrm{MJ} \cdot \mathrm{m}^{-2} \cdot \mathrm{d}^{-1} ; \gamma$ is the psychometric constant, $\mathrm{KP}_{a}{ }^{\circ} \mathrm{C}^{-1} ; u_{2}$ is the wind speed at the height of $2 \mathrm{~m}, \mathrm{~m} \cdot \mathrm{s}^{-1}$; $T$ is the temperature at the height of $2 \mathrm{~m},{ }^{\circ} \mathrm{C} ; e_{s}$ is the saturated water vapor pressure; $e_{a}$ is the actual water vapor pressure, and $\left(e_{s}-e_{a}\right)$ is the saturated water vapor pressure differential value, $\mathrm{K} P_{a}$.

\subsubsection{Mann-Kendall Trend Test}

The Mann-Kendall (MK) test was used to detect regional $\mathrm{ET}_{0}$ trends and hydrological imbalances $[39,40]$. For a given data series, the statistical value $S$ and the standardized test statistics $Z_{M K}$ were calculated as follows [41]:

$$
\begin{gathered}
\mathrm{S}=\sum_{i=1}^{n-1} \sum_{j=i+1}^{n} \operatorname{sgn}\left(X_{j}-X_{i}\right) \\
\operatorname{sgn}\left(X_{j}-X_{i}\right)=\left\{\begin{array}{cc}
+1 & \text { if }\left(X_{j}-X_{i}\right)>0 \\
0 & \text { if }\left(X_{j}-X_{i}\right)=0 \\
-1 & \text { if }\left(X_{j}-X_{i}\right)<0
\end{array}\right. \\
\operatorname{Var}(\mathrm{S})=\frac{1}{18}\left[n(n-1)(2 n+5)-\sum_{p=1}^{q} t_{p}\left(t_{p}-1\right)\left(2 t_{p}+5\right)\right]
\end{gathered}
$$

and 


$$
Z_{M K}=\left\{\begin{array}{cc}
\frac{S-1}{\sqrt{\operatorname{Var}(S)}} & \text { if } S>0 \\
0 & \text { if } S=0 \\
\frac{S-1}{\sqrt{\operatorname{Var}(S)}} & \text { if } S<0
\end{array}\right.
$$

where $X_{i}$ and $X_{j}$ are the values of the year $i$ and $j$ of the time series, $n$ is the length of the time series data, $t_{p}$ is the binding value corresponding to the pth number, and $Z_{M K}$ is the variation trend of the time series data. If $Z_{M K}>0$, the time series data have an increasing trend over time; if the contrary, the data have a decreasing trend. If $\left|Z_{M K}\right|>Z_{(1-a / 2)}$, then the null hypothesis that there is a significant trend in the time series data was rejected. The $Z_{(1-a / 2)}$ values can be found in the standard normal distribution chart. When taking a $=5 \%$ as the significance level, the corresponding value of $Z_{(1-a / 2)}$ is 1.96 ; when taking $a=1 \%$ as the significance level, the corresponding value of $Z_{(1-a / 2)}$ is 2.58 .

\subsubsection{Wavelet Transform Coherence and Contribution Rate Analysis}

Wavelet transform coherence is a new signal analysis technology combining wavelet transform and cross-spectrum analysis. It can study the correlation between two time series in the time-frequency domain from multiple time scales [42]. Wavelet transform coherence was introduced by Hudgins et al. [43] among others. In hydrology, it has been used in rainfall-runoff cross-analysis [44].

$$
\begin{gathered}
R_{n}^{2}(s)=\frac{\left|S\left(s^{-1} W_{n}^{X Y}(s)\right)\right|^{2}}{S\left(s^{-1}\left|W_{n}^{X}(s)\right|^{2}\right) \cdot S\left(s^{-1}\left|W_{n}^{Y}(s)\right|^{2}\right)} \\
\left.S_{\text {time }}(w)\right|_{x}=W_{n}(s) \times\left. c_{1} \frac{-t^{2}}{2 s^{2}}\right|_{s} \\
\left.S_{\text {time }}(w)\right|_{x}=\left.\left(W_{n}(s) \times c_{2} \prod(0.6 s)\right)\right|_{n}
\end{gathered}
$$

Here, $\left|W_{n}^{X Y}(s)\right|$ indicates the cross wavelet power spectrum, $\mathrm{S}$ is the smoothing function, $c_{1}, c_{2}$ are the normalized constants, and $\Pi(0.6 s)$ indicates a rectangular function. In the formula, $Y$ is the standardized value of the $\mathrm{ET}_{0}, X_{1}, X_{2} \cdots X_{n}$ are standardized values of the meteorological parameters, $a_{1}, a_{2} \cdots a_{n}$ are regression coefficients after sequence normalization, $g_{1}$ is the relative contribution rate of $X_{n}$ variation to $Y$ variation.

$$
\begin{gathered}
Y=a_{1} X_{1}+a_{2} X_{2}+a_{3} X_{3}+\cdots+a_{n} X_{n} \\
g_{1}=\frac{\left|a_{1}\right|}{\left|a_{1}\right|+\left|a_{2}\right|+\left|a_{3}\right|+\cdots+\left|a_{n}\right|}
\end{gathered}
$$

\section{Results}

\subsection{Changes in the Annual and Seasonal ET $T_{0}$ of Different Topographic Regions}

Figure 2 shows the seasonal and annual mean $\mathrm{ET}_{0}$ over the entire CLP and the three topographic regions from 1960 to 2017. The annual mean $\mathrm{ET}_{0}$ was $1074 \mathrm{~mm}$ during 1960-2017 in the CLP, and the maximum and minimum values were $1181 \mathrm{~mm}$ and $987 \mathrm{~mm}$, respectively. Comparing the $\mathrm{ET}_{0}$ values of the three topographic regions (MR, HR, and VR), the mean annual $\mathrm{ET}_{0}$ value of the HR $(1078 \mathrm{~mm})$ was larger than that of the MR $(933 \mathrm{~mm})$ and the VR $(1021 \mathrm{~mm})$. Over recent decades, the mean annual $\mathrm{ET}_{0}$ value of the CLP displayed an upward trend of $7.7 \mathrm{~mm} / 10 \mathrm{a}$. There was a decreasing trend during the 1960s and 1970s. During this period, the $\mathrm{ET}_{0}$ value exhibited a decreasing trend of fluctuations from the $1960 \mathrm{~s}(1074 \mathrm{~mm})$ to the $1970 \mathrm{~s}(1052 \mathrm{~mm})$, and then, a relatively stable trend of regional $\mathrm{ET}_{0}$ 
variation occurred in the period of the 1970s to the 1990s. A step increase was observed in 1997. During 2005-2017, the annual $\mathrm{ET}_{0}$ of the CLP showed a decreasing trend.
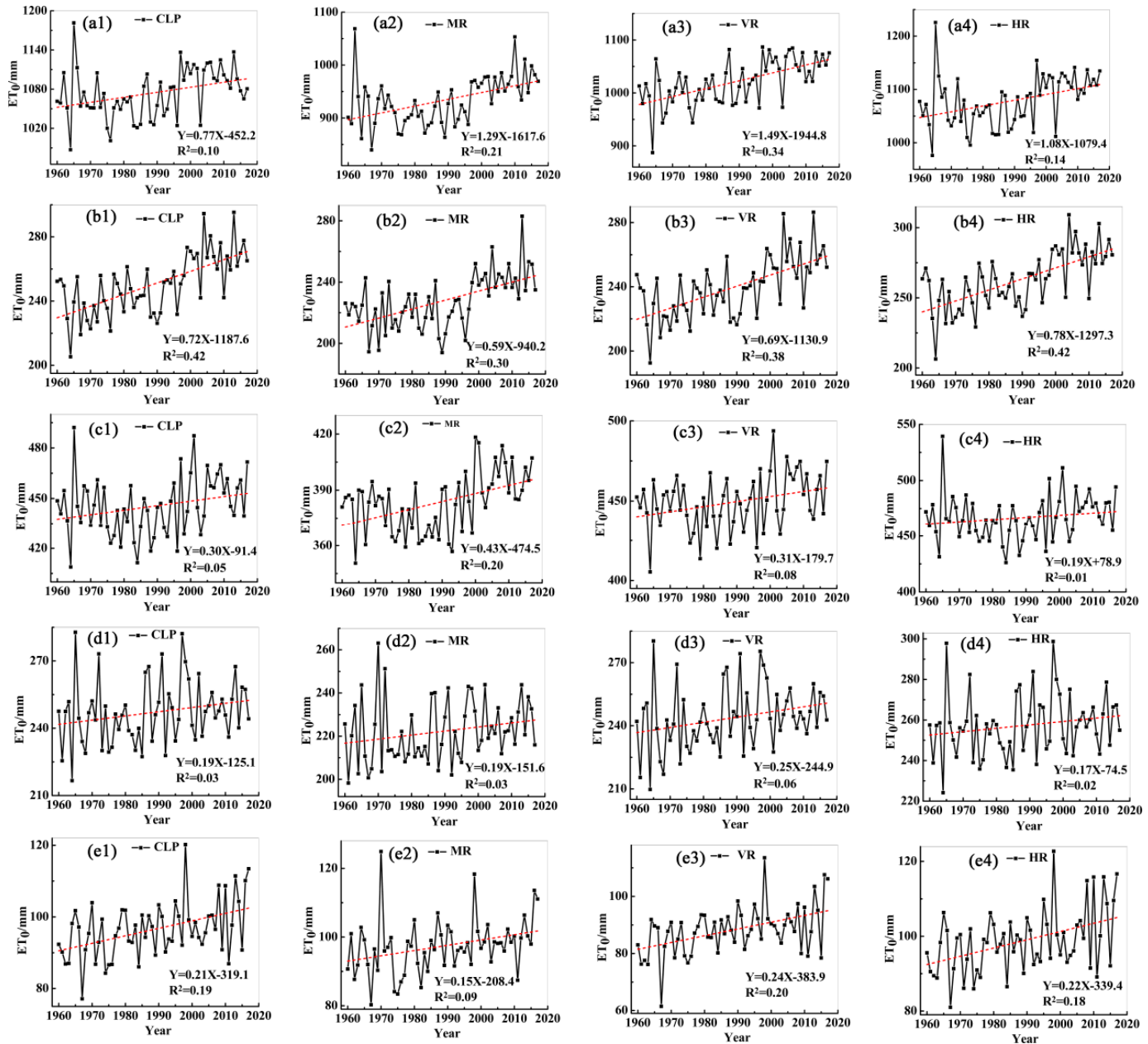

Figure 2. Annual and seasonal variation of $\mathrm{ET}_{0}$ during 1960-2017 in the Loess Plateau (mm); (a) annual (a1 CLP; a2 MR; a3 VR; a4 HR); (b) spring (b1 CLP; b2 MR; b3 VR; b4 HR); (c) summer (c1 CLP; c2 MR; c3 VR; c4 HR); (d) autumn (d1 CLP; d2 MR; d3 VR; d4 HR); (e) winter (e1 CLP; e2 MR; e3 VR; e4 HR).

During the study period, the mean $\mathrm{ET}_{0}$ values in spring, summer, autumn, and winter were 250, 445, 247, and 97mm, respectively. Comparing the four seasons, the mean $\mathrm{ET}_{0}$ value for summer during 1960-2017 was higher than that for winter. A larger temporal variation can be observed in the mean $\mathrm{ET}_{0}$ values for the spring and autumn. For spring (Figure $2 \mathrm{~b}$ ), the $\mathrm{ET}_{0}$ exhibited a relatively consistent value from 1960 to 1990, after which time a remarkable increase can be seen since the 1990s. A similar variation appeared in the mean $\mathrm{ET}_{0}$ for the summer and autumn. A slightly decreasing trend was displayed in the mean $\mathrm{ET}_{0}$ values for the summer and autumn during the period of the $1960 \mathrm{~s}$ to the mid-1980s. From the mid-1980s, the mean $\mathrm{ET}_{0}$ for the summer and autumn showed increasing trends. The temporal variation of the mean $\mathrm{ET}_{0}$ in winter showed a similar trend to that in the spring. Regarding the three topographic regions (MR, $\mathrm{HR}$, and $\mathrm{VR}$ ), the mean $\mathrm{ET}_{0}$ values for the three regions exhibited similar temporal variations in all seasons except for the summer. In summer, the mean $\mathrm{ET}_{0}$ of the MR showed a slightly increasing trend (Figure 2c).

\subsection{Spatial Distribution of Et $t_{0}$ in Different Terrain Regions and Seasons}

Figure 3 shows the spatial patterns of the seasonal and annual $\mathrm{ET}_{0}$ values mean from 1960 to 2017. During 1960-2017, the annual mean $\mathrm{ET}_{0}$ of the CLP was $1044 \mathrm{~mm}$, ranging from 495 to $1467 \mathrm{~mm}$. 
The highest value of $\mathrm{ET}_{0}$ was at the Xiangning station $(1467 \mathrm{~mm})$, and the lowest value was at the Wutaishan station $\left(495 \mathrm{~mm}\right.$ ). The $\mathrm{ET}_{0}$ values in the southern and eastern areas of the CLP were always higher than those in the western part of the CLP (Figure 3), which may be related to the different spatial distributions of the climatic conditions (e.g., T, WS, RH, and SD) and the complicated topography in the CLP. In spring, the maximum mean $\mathrm{ET}_{0}$ value occurred at the Xiangning station $(388 \mathrm{~mm})$ and the minimum mean $\mathrm{ET}_{0}$ value was observed at the Wutaishan station $(100 \mathrm{~mm})$. The mean ET0 values of the VR were higher than those of the MR and HR. In summer, the Xiangning station ( $578 \mathrm{~mm}$ ) displayed the maximum average $\mathrm{ET}_{0}$ value, and the Wutaishan station $(219 \mathrm{~mm})$ displayed the minimum average $\mathrm{ET}_{0}$ value. The average $\mathrm{ET}_{0}$ values of the VR were higher than those of the $\mathrm{HR}$ and MR. As for the autumn, there was a minimum average $\mathrm{ET}_{0}$ value observed at the Wutaishan station $(133 \mathrm{~mm})$, and a maximum average $\mathrm{ET}_{0}$ value occurred at the Xiangning station $(347 \mathrm{~mm})$. In winter, the Xianging station $(155 \mathrm{~mm})$, located in the southeastern part of the Loess Plateau, displayed the maximum average $\mathrm{ET}_{0}$ value, and a minimum average $\mathrm{ET}_{0}$ value occurred at the Wutaishan station $(44 \mathrm{~mm})$. The average $\mathrm{ET}_{0}$ values of the MR were lower than those of the HR and VR.
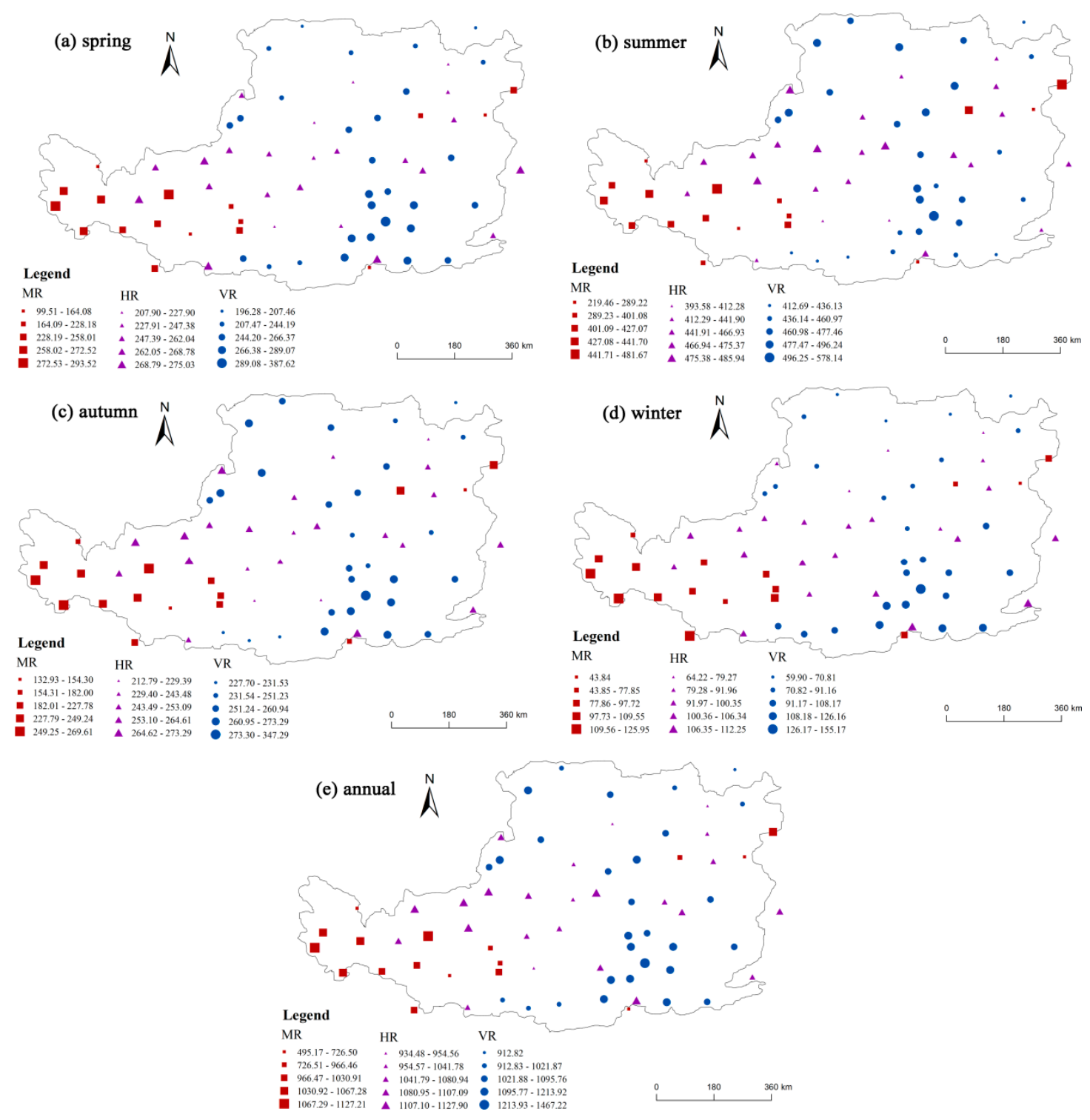

Figure 3. Spatial distribution of variation for annual and seasonal $\mathrm{ET}_{0}$ during 1960-2017. 
In addition, the $\mathrm{ET}_{0}$ of the VR had higher values throughout the entire year, especially in spring and summer. The VR region is an important food-growing area for the CLP, and the higher $\mathrm{ET}_{0}$ values in summer and autumn may result in the regional water shortages being more serious. Therefore, water management should pay more attention to the higher $\mathrm{ET}_{0}$ values of the VR during the spring and summer.

\subsection{Spatial Variation of the Trends of Annual and Seasonal Et $t_{0}$ Series-MK Tests}

Nonparametric Mann-Kendall tests were performed for 70 meteorological stations to analyze trends of annual and seasonal $\mathrm{ET}_{0}$ series in the CLP during 1960-2017 at the 5\% significance level (Figure 4). The annual mean $\mathrm{ET}_{0}$ series of the majority of stations displayed an increasing trend during 1960-2017. Approximately $93 \%$ of stations exhibited a statistically significant increasing trend in the annual mean $\mathrm{ET}_{0}$ series. The annual $\mathrm{ET}_{0}$ of the $\mathrm{HR}$ regions had a stronger significant increasing trend than that of the VR and MR regions. In the HR region, the most significant increasing trend appeared at the Wuzhong station $(6.47 \mathrm{~mm} / \mathrm{a})$, and the slightly increasing trend of the annual mean $\mathrm{ET}_{0}$ was observed at the Xintai $(1.91 \mathrm{~mm} / \mathrm{a})$ and Tongxin $(1.61 \mathrm{~mm} / \mathrm{a})$ stations. In the VR region, the most significant increasing trend occurred at the Xiangning station $(6.39 \mathrm{~mm} / \mathrm{a})$, and the increasing trend of the Mengjin station ( $1.46 \mathrm{~mm} / \mathrm{a}$ ) was not obvious. In the MR region, the annual mean $\mathrm{ET}_{0}$ series had overall significant increasing trends, except for Wushaoling station. However, the increase trend of the Wushaoling station $(0.13 \mathrm{~mm} / \mathrm{a})$ was not obvious.

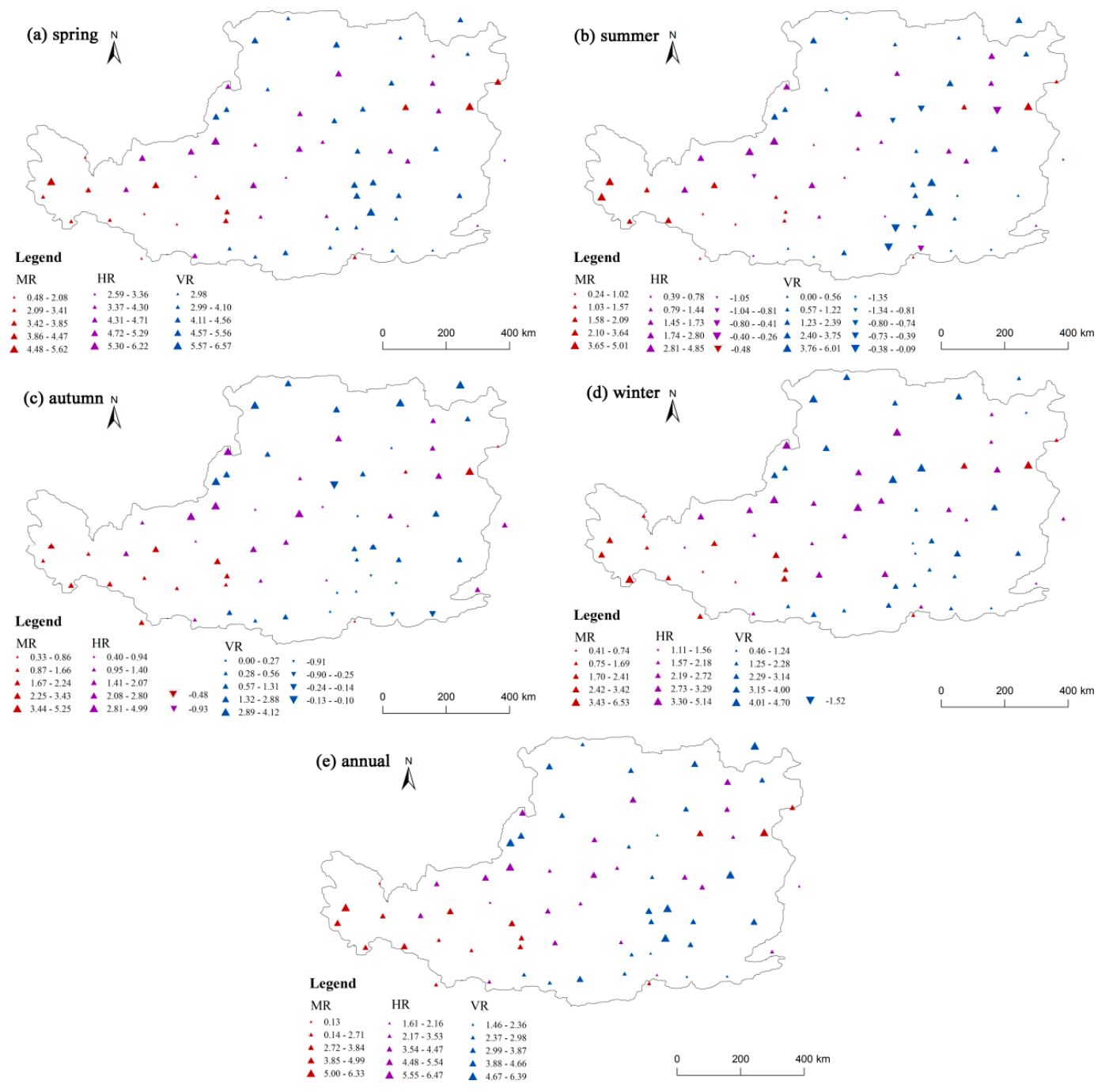

Figure 4. Spatial distribution of variation trends for annual and seasonal $\mathrm{ET}_{0}$ during 1960-2017. 
In spring, the majority of stations showed statistically significant increasing trends, with the largest increase at the Xiangning station $(6.57 \mathrm{~mm} / \mathrm{a})$, and regional magnitudes declined from the VR regions to the MR regions. In summer, 59 stations showed increasing trends, while decreasing trends occurred in the majority of stations in the MR and HR. In autumn, more than $90 \%$ of the total stations showed an increasing trend during 1960-2017, and only six stations (WuQiaoLing, SanMenXia, MengJin, XiangNing, YongJi, YuLin) had statistically significant decreases. In winter, the $\mathrm{ET}_{0}$ exhibited increasing trends at 69 stations, mostly in the MR and HR regions. A decreasing trend was observed at Hequ station, which was located on the eastern edge of the Loess Plateau.

Overall, on a temporal scale, an increasing trend existed in the CLP throughout almost the entire year, especially in spring. On a spatial scale, the seasonal $\mathrm{ET}_{0}$ in the majority of the CLP exhibited increasing trends, and decreasing trends mainly occurred in the HR and VR regions.

\subsection{Wavelet Transform Coherence of Et $t_{0}$ and the Large-Scale Circulation Patterns}

Figure 5 shows the wavelet transform coherence (WTC) results for the $\mathrm{ET}_{0}$ and the large-scale circulation patterns (for example, NAO, Atlantic Multidecadal Oscillation (AMO), Pacific-North American teleconnection (PNA), etc.). For ET0 (Figure 5a), the WTC with NAO had very good negative correlations in the periods of 1980-2000 and 2003-2009, which indicated it to have large interannual covariance at scales of 12-16 and 3-5a, respectively. In the resonance period of 3-5a, its coherence phase angle was $160^{\circ}$, and its coherence phase angle was $210^{\circ}$ in the resonance period of $12-16 \mathrm{a}$. The resonance period of $\mathrm{ET}_{0}$ and $\mathrm{AO}$ in the high-energy region was mainly distributed in the resonance period of approximately 3-6 a in around 2008, and in the resonance period of 10-20 a in 1980-2000 (Figure $5 b$ ). Figure $5 c$ shows that in the cone of influence (COI) region, the resonance period of $\mathrm{ET}_{0}$ and El Niño-Southern Oscillation (ENSO) passing the 95\% red noise test was 3-6 a; there was a significant resonance relationship at this frequency band, and the oscillation cohesion was the strongest. The coherence phase angle between ET0 and ENSO was $-60^{\circ}$, showing the ENSO lags behind the $\mathrm{ET}_{0}$ by around $0.5-1$ year band between 1978 and 1984. This phase change was relatively stable. There was significant coherence power and a consistent phase angle for the period 1983-1993 associated with signals in the 2-6 years band, and in this period the phase angle was $360^{\circ}$, which indicated the $\mathrm{ET}_{0}$ lags about 2-6 a behind PNA (Figure 5d). Similar to the PNA, a significant coherence power and consistent phase appeared in the period 1985-1994 associated with signals in the 2-5 years band and the coherence phase angle of $\mathrm{ET}_{0}$ and $\mathrm{AMO}$ was $-45^{\circ}$, which means that $\mathrm{AMO}$ lags behind $\mathrm{ET}_{0}$ by around $0.25-0.63$ a. The ET0 and WPI showed significant resonance relationships between 6 and 8 years in 1968-1976, reflecting that the $\mathrm{ET}_{0}$ was ahead of WPI; another significant resonance relationship was 7-10 a, and the coherence phase angle of ET0 and WPI was $10^{\circ}$, indicating that $\mathrm{ET}_{0}$ lags behind WPI by around $0.19-0.28$ a (Figure 5f). 
(a) $\mathrm{ET}_{0}-\mathrm{NAO}$

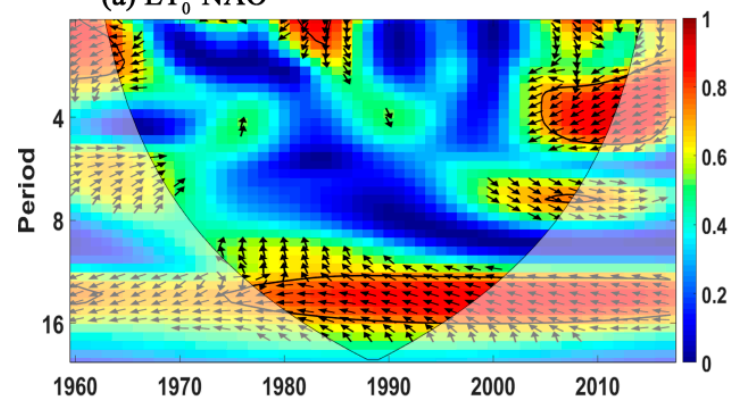

(c) $\mathrm{ET}_{0}$-ENSO

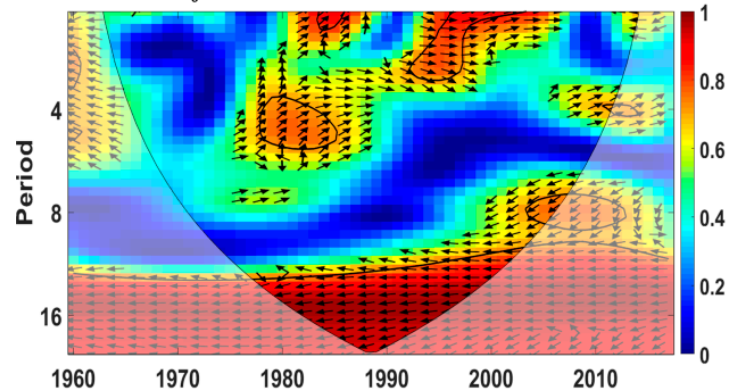

(e) $\mathrm{ET}_{0}$-AMO

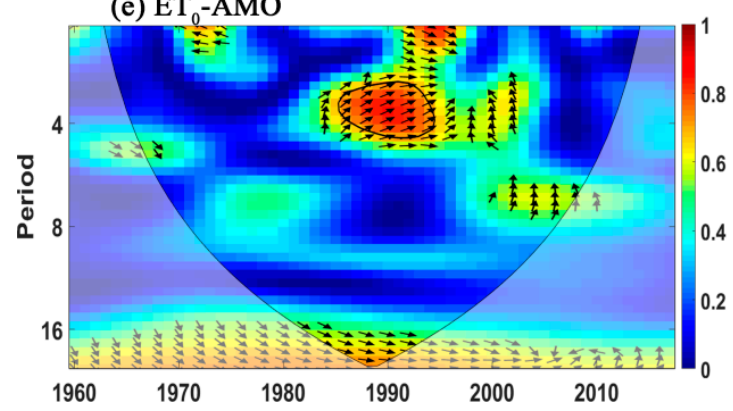

(b) $\mathrm{ET}_{0}-\mathrm{AO}$

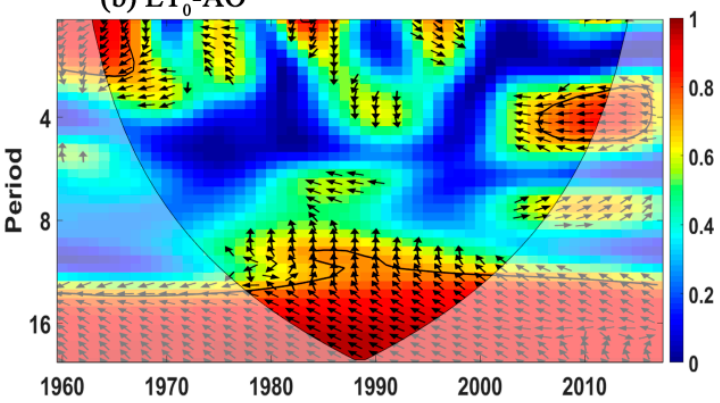

(d) $\mathrm{ET}_{0}$-PNA

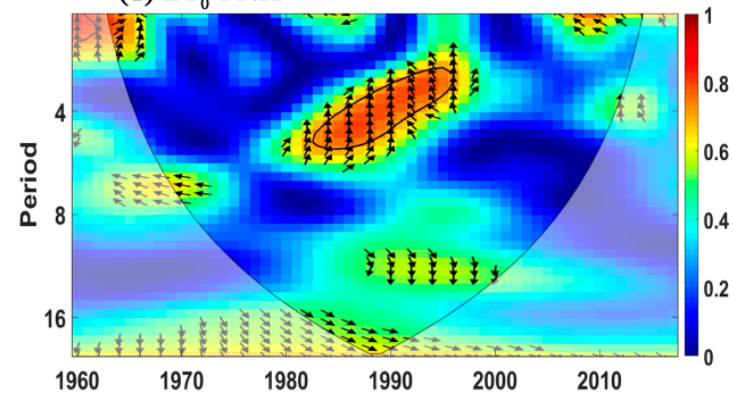

(f) $\mathrm{ET}_{0}$-WPI

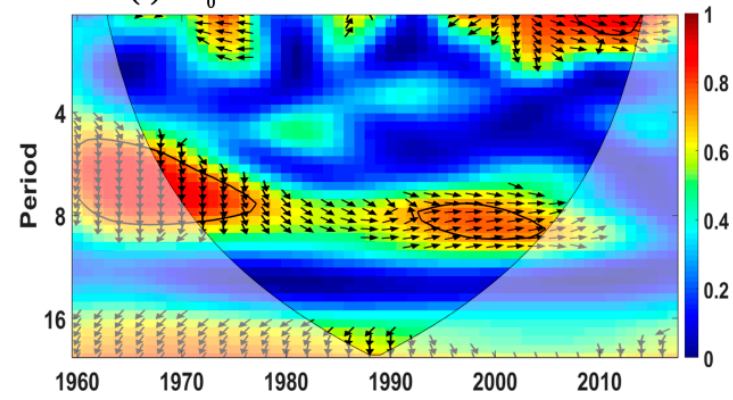

Figure 5. Wavelet transform coherence for $\mathrm{ET}_{0}$ and the large-scale circulation patterns. Thick contours denote $5 \%$ significance levels against red noise. Pale regions denote the Cone of Influence (COI) where edge effects might distort the results. Small arrows denote the relative phase relationship (in-phase, arrows point right; anti-phase, arrows point left).

\section{Discussion}

\subsection{Relationships between Regional Et0 and Climatic Factors}

Table 2 shows the correlation coefficients between the $\mathrm{ET}_{0}$ and the meteorological parameters. In the CLP, the regional RH variation had a significant association with the variation of the $\mathrm{ET}_{0}$ (i.e., the correlation coefficient is 0.76 ). In addition, there is an obvious correlation between the variation of regional $\mathrm{ET}_{0}$ and $\mathrm{Tmax} / \mathrm{T}$. Regarding the three geomorphic regions, higher correlation coefficients between the regional $\mathrm{ET}_{0}$ variation and Tmax variation were observed at the MR (0.77) and VR (0.84) regions. For the $\mathrm{HR}$ region, the regional $\mathrm{ET}_{0}$ displayed the most remarkable (i.e., passed the 0.1 level test) association with the variation of $\mathrm{RH}$, followed by the variations of Tmax and $\mathrm{T}$. According to the results in Table 2, the main meteorological controlling parameters for the regional variation of $\mathrm{ET}_{0}$ in the CLP were $\mathrm{RH}, \mathrm{T}$, and Tmax, which indicated that regional $\mathrm{ET}_{0}$ is more sensitive to the variations in regional relative humidity and air temperature.

However, the influences of meteorological controlling parameters on regional $\mathrm{ET}_{0}$ variations have spatial variation among the three topographic regions. There is a remarkable correlation relationship between the variation of regional $\mathrm{T}$ and the regional $\mathrm{ET}_{0}$, and variations in regional $\mathrm{RH}$ and $\mathrm{T}$ may 
cause regional $\mathrm{ET}_{0}$ variability. Besides, the WS plays an important role in regional $\mathrm{ET}_{0}$ variation, whereas the $\mathrm{SD}$ has no significant association with the variation of regional $\mathrm{ET}_{0}$.

Table 2. The correlation coefficient between potential evapotranspiration and climatic factors.

\begin{tabular}{ccccccc}
\hline & WS & T & Tmax & Tmin & SD & RH \\
\hline CLP & $-0.363^{* *}$ & $0.605^{* *}$ & $0.717^{* *}$ & $0.416^{* *}$ & $0.303^{*}$ & $0.757^{* *}$ \\
MR & $-0.31^{*}$ & $0.69^{* *}$ & $0.773^{* *}$ & $0.603^{* *}$ & 0.175 & $-0.69^{* *}$ \\
VR & $-0.326^{*}$ & $0.749^{* *}$ & $0.84^{* *}$ & $0.579^{* *}$ & 0.08 & $-0.709^{* *}$ \\
HR & $-0.489^{* *}$ & $0.61^{* *}$ & $0.703^{* *}$ & $0.442^{* *}$ & 0.137 & $-0.713^{* *}$ \\
\hline
\end{tabular}

* Significantly correlated at the 0.05 level; ** Significantly correlated at the 0.1 level.

To assess the contributions of the main meteorological controlling parameters to the regional $\mathrm{ET}_{0}$ variation in the entire CLP, the contribution rates were analyzed using the method contribution rate analysis. The results (Table 3) show the $\mathrm{T}$ variation had the highest contribution rate $(42 \%)$. The variations of $\mathrm{RH}, \mathrm{WS}$, and SD made smaller contributions to the $\mathrm{ET}_{0}$ in the CLP. As for the MR region, the largest contribution rate for the regional $\mathrm{ET}_{0}$ variation was $\mathrm{T}$ variation $(40 \%)$, followed by variations of Tmax (26\%), Tmin (26\%), SD (4\%), RH (4\%), and WS (1\%). As for the VR region, the contribution rate pattern had a similar order to that of the MR region. As for the $\mathrm{ET}_{0}$ variation in the HR region, the variation of Tmax displayed the highest contribution rate (39\%). The contribution rates of the regional WS, SD, and RH were also relatively low. In short, we can conclude that the variation of regional $\mathrm{ET}_{0}$ in the CLP was mainly controlled by regional air temperature variations, while the influences of the regional WS, $\mathrm{SD}$, and $\mathrm{RH}$ on regional $\mathrm{ET}_{0}$ variation were relatively weak.

Table 3. The contribution rate of climatic parameters to the variation of the $\mathrm{ET}_{0}(\%)$.

\begin{tabular}{ccccccc}
\hline & WS & T & Tmax & Tmin & SD & RH \\
\hline CLP & 7 & 42 & 13 & 23 & 7 & 8 \\
MR & 1 & 40 & 26 & 26 & 4 & 4 \\
VR & 7 & 39 & 10 & 28 & 1 & 15 \\
HR & 1 & 11 & 39 & 17 & 4 & 28 \\
\hline
\end{tabular}

\subsection{Comparison with Other Study Areas}

Recently, some researchers have paid increasing attention to assessing regional $\mathrm{ET}_{0}$ variations. Due to the different environments in various regions, temporal and spatial variations of the $\mathrm{ET}_{0}$ in different regions have been proven to have significant differences (Table 4). In a study of the $\mathrm{ET}_{0}$ for the whole of China, researchers found that the overall $\mathrm{ET}_{0}$ variations in China showed a downward trend [45]. This same variation was also found in the northwestern part of China [28]. However, in the southwestern part of China [46], the Wei River basin [47], and the Yangtze River [48], the $\mathrm{ET}_{0}$ had increasing trends. The trend of the CLP is the opposite to the trend of the whole of China. Comparing the $\mathrm{ET}_{0}$ trend in the three topographic regions (MR, $\mathrm{HR}$, and $\mathrm{VR}$ ), the trend of the $\mathrm{ET}_{0}$ in the VR $(1.49 \mathrm{~mm} / \mathrm{a})$ was larger than in the MR $(1.28 \mathrm{~mm} / \mathrm{a})$ and HR $(1.09 \mathrm{~mm} / \mathrm{a})$.

Table 4. The information of the $\mathrm{ET}_{0}$ in other parts of China and the whole of China during the past decades.

\begin{tabular}{ccccc}
\hline Study Area & Time Period & Trends & Abrupt Change & Sources \\
\hline Northwest China & $1958-2008$ & decrease & 1978 & {$[32]$} \\
Southwest China & $1961-2009$ & increase & 1985 & {$[46]$} \\
Wei River Basin, China & $1959-2008$ & increase & 1993 & {$[47]$} \\
Yangtze River, China & $1960-2011$ & increase & 2000 & {$[48,49]$} \\
Whole of China & $1960-2013$ & decrease & 1993 & {$[45]$} \\
CLP, China & $1960-2017$ & increase & 1997 & This study \\
\hline
\end{tabular}




\section{Conclusions}

During the period of 1960-2017, the mean annual $\mathrm{ET}_{0}$ of the CLP was $1074 \mathrm{~mm}$, and the maximum and minimum values were $1181 \mathrm{~mm}$ and $987 \mathrm{~mm}$, respectively. The trends of $\mathrm{ET}_{0}$ in three different topographies were generally the same, however, the $\mathrm{ET}_{0}$ values differed. The $\mathrm{ET}_{0}$ in the $\mathrm{HR}$ was the highest of the three regions, followed by the $\mathrm{VR}$, and the $\mathrm{ET}_{0}$ in the MR was the lowest. The magnitude of the $\mathrm{ET}_{0}$ varied in different seasons; in spring, summer, and autumn, the magnitudes of the $\mathrm{ET}_{0}$ were consistent with the annual $\mathrm{ET}_{0}$ variation, which was the largest in the $\mathrm{HR}$, the second-largest in the VR, and the smallest in the MR. In winter, the $\mathrm{ET}_{0}$ values of the $\mathrm{HR}$ and $\mathrm{MR}$ were very similar, while the $\mathrm{ET}_{0}$ of the VR was the smallest.

The spatial distribution of the annual $\mathrm{ET}_{0}$ in the study area varied in different topographies. The $\mathrm{ET}_{0}$ value in the MR decreased from west to east, and the distribution of the $\mathrm{ET}_{0}$ in the $\mathrm{HR}$ was consistent with the MR. The larger $\mathrm{ET}_{0}$ values in the VR were mainly concentrated in the eastern CLP, and the rest were mostly distributed in Inner Mongolia. In the four seasons of comparative analysis, the larger values of the MR were distributed in the western region, and the $\mathrm{ET}_{0}$ distributions in the HR and VR differed. The annual mean $\mathrm{ET}_{0}$ series of the majority of stations displayed increasing trends during 1960-2017. Approximately $93 \%$ of stations exhibited a statistically significant increasing trend for the annual mean $\mathrm{ET}_{0}$ series. The annual $\mathrm{ET}_{0}$ of the $\mathrm{HR}$ regions had a stronger significant increasing trend than that of the VR and MR regions.

The wavelet transform coherence results of $\mathrm{ET}_{0}$ and large-scale circulation factors showed that $\mathrm{ET}_{0}$ had significant correlation with ENSO, PNA, and AMO. The resonance period of $\mathrm{ET}_{0}$ and $\mathrm{ENSO}$ was 3-6 a, mainly in 1976-1985. The resonance period of ET $_{0}$ and PNA was mainly in 1983-1993; the average coherence phase angle was close to $360^{\circ}$, indicating that the $\mathrm{ET}_{0}$ lags behind the PNA by about 2-6 a; $\mathrm{ET}_{0}$ had a very good positive correlation with $\mathrm{AMO}$, and its significant resonance period was $2-5$ a.

The RH, T, and Tmax are important meteorological parameters for the variation of control of regional $\mathrm{ET}_{0}$. In the $\mathrm{CLP}, \mathrm{RH}$ is the main influencing parameter of the $\mathrm{ET}_{0}$ variation; however, in the MR and VR, the correlation coefficients of Tmax were the largest ( 0.77 and 0.84 , respectively). The correlation coefficient of the RH in the HR was 0.71 , which is the main controlling parameter. The temperature variation had the highest contribution rate $(42 \%)$ for the regional $\mathrm{ET}_{0}$ variation in the entire CLP. As an important controlling factor for the regional energy balance, temporal-spatial variation of evaporation usually resulted in the regional water cycle rate increasing and further affected the regional water-heat balance and ecological security. We should pay more attention to the variation of evaporation under climate change, especially temperature change.

Author Contributions: Conceptualization, C.S.; methodology, Z.Z. and Y.W.; resources, C.S.; writing, original draft preparation, C.S. and Z.Z.; writing, review and editing, C.S. and W.C.; supervision, W.C.; funding acquisition, C.S. All authors have read and agreed to the published version of the manuscript.

Funding: This research was funded by "National Natural Science Foundation of China (Grant No. 41901022 and 41601317)" and "the Foundation for Applied Basic Research Program, Shanxi Province, China(201901D211388)".

Acknowledgments: We are grateful for editor and anonymous reviewers for their constructive comments and suggestions.

Conflicts of Interest: The authors declare no conflict of interest.

\section{References}

1. Han, M.W.; Zhao, G.J.; Mu, X.M.; An, Z.F.; Gao, P.; Sun, W.Y. Spatial and temporal variations of potential evapotranspiration on the Loess Plateau during 1959-2015. Arid Reg. Geogr. 2017, 40, 997-1004. (In Chinese)

2. Liu, W.; Cao, M.M.; Qiu, H.J.; Guo, S.; Li, R. Spatial and temporal change of the potential evapotranspiration in Weihe River Basin: A case study in Guanzhong Area. Sci. Geogr. Sin. 2014, 34, 1145-1152. [CrossRef]

3. Bowen, G.J. A faster water cycle. Science 2011, 332, 430-431. [CrossRef] 
4. Yang, Z.S.; Zhang, Q.; Hao, X.C.E. Characteristics of surface evapotranspiration and its response to precipitation in Loess Plateau from 1982 to 2013. In Proceedings of the Annual Meeting of the China Meteorological Society Arid Land Surface Processes and Climate Change in S5, Tianjin, China, 18 May 2015.

5. Durack, P.J.; Wijffecs, S.E.; Matear, R.J. Ocean salinities reveal strong global water cycle intensification during 1950 to 2000. Science 2012, 336, 455-458. [CrossRef]

6. Keisling, B.A.; Castañeda, I.S.; Brighamgrette, J. Hydrological and temperature change in Arctic Siberia during the intensification of Northern Hemisphere Glaciation. Earth PlanetaryScienceLetters. 2017, 457, 136-148. [CrossRef]

7. Arnell, N.W.; Lowe, J.A.; Challinor, A.J.; Osborn, T.J. Global and regional impacts of climate change at different levels of global temperature increase. Clim. Chang. 2019, 155, 377-391. [CrossRef]

8. Qiu, G.Y.; Li, H.Y.; Zhang, Q.T.; Chen, W.; Liang, X.J.; Li, X.Z. Effects of evapotranspiration on mitigation of urban temperature by vegetation and urban agriculture. J. Integr. Agric. 2013, 12, 1307-1315. [CrossRef]

9. Gentilucci, M.; Barbieri, M.; Burt, P. Climate and Territorial Suitability for the Vineyards Developed Using GIS Techniques. In Exploring the Nexus of Geoecology, Geography, Geoarcheology and Geotourism: Advances and Applications for Sustainable Development in Environmental Sciences and Agroforestry Research; Springer: Cham, Switzerland, 2019; pp. 11-13.

10. Song, N.; Sun, J.S.; Wang, J.L.; Chen, Z.F.; Qiang, X.M.; Liu, Z.G. Analysis of difference in crop coefficients based on modified Penman and Penman-Monteith equations. Trans. Chin. Soc. Agric.Eng. 2012, 29, 88-97.

11. Berti, A.; Tardivo, G.; Chiaudani, A.; Rech, F.; Borin, M. Assessing reference evapotranspiration by the Hargreaves method in north-eastern Italy. Agric. Water Manag. 2014, 140, 20-25. [CrossRef]

12. Zhao, L.L.; Wang, Z.G.; Xia, J.; Chen, X.; Qin, N.X. Improved Priestley-Taylor Method and its application in complementary relationship evapotranspiration model. Prog. Geogr. 2011, 30, 805-810.

13. Allen, R.G.; Pereira, L.S.; Raes, D.; Smith, M. Crop Evapotranspiration: Guidelines for Computing Crop Water Requirements; Irrigation and Drainage Paper 56; Food and Agricultural Organization: Rome, Italy, 1998.

14. Sun, S.L.; Chen, H.S.; Sun, G.; Ju, W.M.; Wang, G.J.; Li, X.; Yan, G.X.; Gao, C.J.; Huang, J.; Zhang, F.M. Attributing the changes in reference evapotranspiration in Southwestern China using a new separation method. J. Hydrometeorol. 2017, 18, 777-798. [CrossRef]

15. Tang, R.L.; Li, Z.L.; Sun, X.M.; Bi, Y.Y. Temporal up scaling of instantaneous evapotranspiration on clear-sky days using the constant reference evaporative fraction method with fixed or variable surface resistances at two cropland sites. J. Geophys. Res. Atmos. 2017, 122, 784-801. [CrossRef]

16. Abtew, W.; Obeysekera, J.; Iricanin, N. Pan evaporation and potential evapotranspiration trends in South Florida. Hydrol. Process. 2015, 25, 958-969. [CrossRef]

17. Ye, H.; Zhang, T.B.; Yi, G.H.; Li, J.J.; Bie, X.J.; Liu, D.; Luo, L.L. Spatio-temporal characteristics of evapotranspiration and its relationship with climate factors in the source region of the Yellow River from 2000 to 2014. Acta Geogr. Sin. 2018, 73, 2117-2134.

18. Zhou, B.R.; Li, F.X.; Xiao, H.B.; Hu, A.J.; Yan, L.D. Characteristics and climate explanation of spatial distribution and temporal variation of potential evapotranspiration in Headwaters of the Three Rivers. J. Nat. Resour. 2014, 29, 2068-2077.

19. Piticar, A.; Mihăilă, D.; Lazurca, L.G.; Bistricean, P.I.; Puţuntică, A.; Briciu, A.E. Spatiotemporal distribution of reference evapotranspiration in the Republic of Moldova. Theor. Appl. Climatol. 2016, 124, 1133-1144. [CrossRef]

20. Danlu, G.; Seth, W.; Maier, H.R. Sensitivity of potential evapotranspiration to changes in climate variables for different Australian climatic zones. Hydrol. Earth Syst. Sci. 2017, 21, 2107-2126.

21. Mohammad, V. Analysis of potential evapotranspiration using limited weather data. Appl. Water Sci. 2017, 7, 187-197.

22. Swapnil, S.V.; Rahul, N.; Bimal, K.B.; Prashant, K. Development of real-time reference evapotranspiration at the regional scale using satellite-based observations. Int. J. Remote Sens. 2016, 37, 6108-6126.

23. Liu, P.X.; Zhuoma, L.C. Spatial and temporal variation of potential evapotranspiration in Gansu province from 1960 to 2008 and its influencing factors. J. Nat. Resour. 2012, 27, 1561-1571.

24. Zhu, G.F.; He, Y.Q.; Pu, T.; Li, Z.X.; Wang, X.F.; Jia, W.X.; Xin, H.J. Spatial distribution and temporal trends in potential evapotranspiration over Hengduan Mountains region from 1960 to 2009. Acta Geogr. Sin. 2012, 66, 905-916. [CrossRef] 
25. Zhang, L.X.; Zhang, W.X.; Zhou, T.J.; Wu, B.E. Assessment of the decadal prediction skill on global land summer monsoon precipitation in the coupled models of Ensembles. Adv. Earth Sci. 2017, 32, 409-419.

26. Gao, G.; Chen, D.L.; Ren, G.Y.; Chen, Y.; Liao, Y.M.E. Spatial and temporal variations and controlling factors of potential evapotranspiration in China: 1956-2000. J. Geogr. Sci. 2006, 16, 3-12. [CrossRef]

27. Tang, J.; Cao, H.Q.; Chen, J. Changes of hydro-meteorological factors and the relationships with large-scale circulation factors in the source region of the Yangtze River. J. Nat. Resour. 2018, 33, 122-134.

28. Wang, T.T.; Sun, F.B.; Zhang, J.; Liu, W.B.; Wang, H. Anew method to attribute changes of pan evaporation: The experimental detrending approach. Acta Geogr. Sin. 2018, 73, 2064-2074.

29. Gong, D.E.; Wang, S.W. Influence of atmospheric oscillations on northern hemispheric temperature. Geogr. Res. 1999, 18, 31-38.

30. Li, P.; Huang, S.Z.; Huang, Q.; Ma, L.; Wu, H.S.; Luan, J.K. Study on the evolution characteristics and driving forces of rainfall structure in Datong River Basin. J. Nat. Resour. 2018, 33, 1588-1598.

31. Yao, Y.J.; Zhao, S.H.; Zhang, Y.H.; Jia, K.; Liu, M. Spatial and decadal variations in potential evapotranspiration of China based on reanalysis datasets during 1982-2010. Atmosphere. 2014, 5, 737-754. [CrossRef]

32. Wang, Y.M.; Zhang, B.; Dai, S.P.; Wang, H.J.; Guo, L.X.; Kang, S.Y. Analysis of spatial distributions and temporal trends in potential evaporation over Hexi Areas from1960 to2008. Resour. Sci. 2010, 32, 139-148.

33. Zhou, B.R.; Li, F.X.; Xaio, H.B.; Hu, A.J.; Yan, L.D. Spatial and temporal differentiation and climatic attribution of potential evapotranspiration in sanjiangyuan area. J. Nat. Resour. 2014, 29, 2068-2077.

34. Zhao, Y.F.; Zou, X.Q.; Zhang, J.X.; Cao, L.G.; Xu, X.W.H.; Zhang, K.X.; Chen, Y.Y. Spatio-temporal variation of reference evapotranspiration and aridity index in the Loess Plateau Region of China, during 1961-2012. Quat. Int. 2014, 349. [CrossRef]

35. Tingting, N.; Li, Z.; Liu, W.Z.; Han, X.Y. Evolution of potential evapotranspiration in the northern Loess Plateau of China: Recent trends and climatic drivers. Int. J. Climatol. 2016, 36, 4019-4028.

36. Zhang, X.P.; Li, Z.Q.; Wang, M.B.; Wang, X.G. Classification and ordination of grassland landscape in the Shanxi Plateau. Acta Ecol. Sin. 2014, 34, 3386-3395.

37. Cheng, P. Vegetation Coverage Variations and Its Mechanism Based on Remotely Sensed Technology on Shanxi Plateau; Taiyuan University of Technology: Taiyuan, China, 2016.

38. Fu, B.J.; Liu, Y.; Lv, Y.H.; He, C.S.; Zeng, Y.A.; Wu, B.F. Assessing the soil erosion control service of ecosystems change in the Loess Plateau of China. Ecol. Complex. 2011, 8, 284-293. [CrossRef]

39. Hamed, K.H. Trend detection in hydrologic data: The Mann-Kendall trend test under the scaling hypothesis. J Hydrol. 2008, 349, 350-363. [CrossRef]

40. Sun, S.K.; Wu, P.; Wang, Y.B.; Zhao, X.N.; Liu, J.; Zhang, X.H. Impacts of climate change on water footprint of spring wheat production: The case of an irrigation district in China. Span. J. Agric. Res. 2012, 10, N4. [CrossRef]

41. Wei, G.H.; Deng, L.J. Analysis on precipitation trend in arid regions based on nonparametric verification methods of Mann-Kendall and spearman's rho. Northwest Hydropower 2014, 4, 1-4.

42. Yu, D.D.; Zhang, R.; Hong, M.; Liu, K.F.; Wang, H.Z. Correcation analysis between the west Pacific subtropical high and the east Asian summer monsoon system based on cross wavelet and wavelet coherence. J. Nanjing Inst. Meteorol. 2007, 30, 755-769.

43. Hudgins, L.; Friehe, C.; Mayer, M. Wavelet transforms and atmospheric turbulence. APS Phys. Rev. 1993, 71, 3279-3282.

44. Labat, D.; Rachid, A.; Mangin, A. Wavelet analysis in Karstic hydrology. 2nd part: Rainfall-runoff cross wavelet analysis. C. R. Acad. Sci. Ser. IIA Earth Planet. Sci. 1999, 329, 881-887.

45. Huang, H.P.; Han, Y.P.; Cao, M.M.; Song, J.X.; Xiao, H.; Cheng, W.L. Spatiotemporal characteristics of evapotranspiration paradox and impact factors in China in the period of 1960-2013. Adv. Meteorol. 2015, 1-10. [CrossRef]

46. Li, Z.X.; Feng, Q.; Liu, W.; Wang, T.T.; Gao, Y.; Wang, Y.M.; Cheng, A.F.; Li, J.G.; Liu, L. Spatial and temporal trend of potential evapotranspiration and related driving forces in Southwestern China, during 1961-2009. Quat. Int. 2014, 336, 127-144.

47. Zuo, D.P. Spatiotemporal variations and abrupt changes of potential evapotranspiration and its sensitivity to key meteorological variables in the Wei River basin, China. Hydrol. Process. 2012, 26, 1149-1160. [CrossRef] 
48. Wang, R.; Chen, A.J.; He, X.G. Analysis on spatiotemporal variability of monthly precipitation and its lag correlation with AO and NAO in Yangtze River Basin. J. Meteorol. Sci. 2018, 38, 730-738.

49. $\mathrm{Xu}, \mathrm{Y}$.; $\mathrm{Wu}, \mathrm{Y}$.F.; $\mathrm{Xu}, \mathrm{G}$. Variation of reference evapotranspiration and its teleconnection with multiple large-scale climate oscillations in the Yangtze River Delta, China. Int. J. Climatol. 2019, 39, 2630-2645. [CrossRef] 